\title{
ENTRE SEGURANÇA E LIBERDADE: desafios da comunidade na contemporaneidade
}

por Maria Medrado Nascimento*

BAUMAN, Zygmunt. Comunidade: a busca por segurança no mundo atual. Rio de Janeiro: Jorge Zahar, 2003. 144 p.

"As palavras têm significado: algumas delas, porém, guardam sensações. A palavra 'comunidade' é uma dessas”. É assim que o sociólogo polonês Zygmunt Bauman introduz a sua obra Comunidade: a busca por segurança no mundo atual. Com seu estilo próprio de abordar as questões da modernidade, reluzentes no mundo urbano, o autor irá centrar a sua análise na noção de "comunidade" e o paradoxo que este conceito traz: se por um lado ela emana uma sensação boa, de se ter com quem contar, tudo que um citadino - imerso em um mundo impessoal - precisa para viver tranqüilo e confiante, por outro lado limita uma das maiores conquistas modernas: a liberdade individual. $\mathrm{O}$ grande dilema que se abre aqui é o de que a balança entre segurança e liberdade não encontra uma média exata e, conseqüentemente, uma tende para cima enquanto outra tende para baixo. Segurança e liberdade nunca vêm na mesma proporção e por isso não podemos ter ambas ao mesmo tempo e na quantidade que quisermos.

O desequilíbrio na balança segurança/liberdade no contexto comunitário ressalta a diferença entre a antiga e a moderna

* Mestranda em Sociologia na Universidade de Brasília (UnB). 
comunidade. Sobre a base teórica formulada por Ferdinand Tonnies, Bauman afirma que a antiga comunidade se baseia em um entendimento compartilhado por todos os seus membros e que não precisa ser procurado, pois, já está lá: entendido sem que nem houvesse palavras, emanando um sentimento recíproco e vinculante, que passa despercebido por sua evidência e naturalidade. Como define o autor, uma negociação prolongada que pode resultar em um acordo que, sendo obedecido cotidianamente, torna-se um hábito e não precisa mais ser repensado, monitorado ou controlado. Tal como Tonnies, Robert Redfield acredita que em uma verdadeira comunidade não há motivo para reflexão, crítica ou experimentação, pois a unidade da comunidade ou a naturalidade do entendimento tem o mesmo fundamento: a homogeneidade, a mesmidade.

É exatamente essa mesmidade que entrará em conflito quando os limites entre a comunicação "de dentro" e "de fora" se tornam mais tênue, tornando ainda mais confusa a distinção entre "nós" e "eles". Em um contexto de modernidade, onde as bruscas mudanças no tempo das comunicações rompem a fronteira entre o "dentro" e o "fora", cabe então uma outra formatação para a idéia de "comunidade". Assim, a idéia de "identidade" ganha vigor. Para o autor, "identidade" significa aparecer, ser diferente e singular. Para qualquer um dos lados da moeda, há que se pagar um preço, pois da mesma forma que segurança sem liberdade equivale à escravidão, a liberdade sem segurança equivale a estar perdido e abandonado.

Para elucidar esta questão teórica tão bem construída, vale considerar o estudo realizado por Norbert Elias e John Scotson (2000) no final dos anos 50. Em Winston Parva, nome fictício da pequena comunidade estudada, o conflito existente entre os "estabelecidos" e os outsiders, expressão que intitula a obra, evidencia as diferenças entre os dois grupos. Enquanto que os estabelecidos apresentavam um alto grau de homogeneidade, coesão social e objetivos comuns referentes à defesa dos seus padrões morais, os outsiders eram marcados pelos fracos laços de solidariedade social que deixavam o terreno fértil para que o estigma lançado pelos "estabelecidos" 
fosse internalizado pelo grupo e evidenciado numa falta de orgulho e baixa estima coletiva.

Entretanto, o alto grau de coesão social presente no grupo dos "estabelecidos" não custou barato. Para tal aquisição um alto preço foi pago: a submissão e a conformidade dos indivíduos às normas comunitárias e a relativa perda de espontaneidade de seus membros. Essas características do grupo dos estabelecidos fogem à média encontrada na sociedade da atualidade, uma vez que a individualização tornou-se a sua marca registrada. Nesta perspectiva, Bauman analisa o processo de industrialização, em que as "massas" foram tiradas da rígida rotina da interação comunitária governada pelo hábito e colocadas na rígida rotina do chão da fábrica governado pelo desempenho de tarefas. Desmorona-se a comunidade onde as intrincadas teias de interações humanas que dotava o trabalho de sentido e objetivo passam a se posicionar como equipes de fábrica regidas por uma rotina artificial imposta.

A partir destas análises, Bauman conclui que duas tendências acompanharam a história do capitalismo moderno. A primeira foi um esforço consistente de substituir o "entendimento natural" da comunidade, seu ritmo e sua rotina por uma outra rotina artificialmente projetada e monitorada. A segunda, uma tentativa de recriar um "sentido de comunidade" adaptado à nova estrutura de poder pautada na dinâmica e na rotinização do processo de produção, na impessoalidade da relação entre trabalhador e máquina, na fixação das tarefas de produção e na homogeneidade das ações dos trabalhadores.

Os pontos de orientações firmes e sólidos de uma sociedade pré-industrial se decompõem e o tempo de uma vida individual insegura se abre. Os laços sociais se enfraquecem na mesma medida em que enfraquecem as lealdades pessoais. Bauman afirma que é neste contexto que a comunidade entra em decadência e a união do que foi rompido parece não mais se suceder. Esta idéia de elo rompido, imerso em um mundo de incertezas, converge com a análise sociopsicanalítica que Eric Fromm faz sobre as necessidades 
humanas. Fromm (2000) argumenta que, ao nascer, o homem é tirado de uma situação definida e é jogado numa situação indefinida, incerta e aberta. A consciência - tanto de nós mesmos como dos outros - permite que nos entendamos como seres separados do mundo, desamparados e incapazes. Este estado de separação é fonte de uma ansiedade imensa que acarreta vergonha e sentimento de culpa, tal como expresso na história bíblica de Adão e Eva que, após o pecado inicial que os transformou em humanos, se emanciparam da harmonia animal original com a natureza e conceberam para si um sentimento de solidão. Mas, como superar esse estado de separação? Como alcançar a união? Como transcender sua vida individual e encontrar a conciliação? Segundo Fromm, as respostas dependem do grau de individuação alcançado.

O sentido de comunidade tratado por Bauman decorre justamente desta busca por segurança e proteção, de estar no mundo unido e podendo contar com os outros. Os diferentes graus de individuação apresentam uma relação com as diferentes classes sociais. Carregando certa ironia em suas linhas, dedica um capítulo do livro a uma análise sobre "a secessão dos bem-sucedidos" referindo-se "ao novo distanciamento, indiferença, desengajamento e, em verdade, à extraterritorialidade mental e moral daqueles que não se importam de ficar sós, desde que os outros, que pensam diferente, não insistam em que se ocupem e muito menos partilhem sua vida por conta própria” (p. 49).

Ou seja, o grupo de privilegiados sociais - "elite global" formado pelos que não precisam mais dos serviços da comunidade, não conseguindo compreender o que ganhariam permanecendo "na" e "com" a comunidade, mas no que poderiam perder se eles se submetessem às demandas da solidariedade comunitária, formariam as "comunidades cercadas", eletronicamente protegidas e controladas. Essa "elite global" - formada pelos que podem ser denominados também de "globalizados" - integra-se com a idéia de um "cosmopolitismo seletivo". A principal celebração deste estilo de vida, segundo o autor, "é a irrelevância do lugar, uma condição inteiramente fora do alcance das pessoas comuns, dos 'nativos' 
estreitamente presos ao chão e que (caso decidam desconsiderar os grilhões) vão encontrar no amplo mundo lá fora funcionários da imigração pouco amigáveis e severos em lugar dos sorridentes recepcionistas dos hotéis" (p. 54).

A "bolha" em que a elite cosmopolita global se aparta do mundo real é uma zona livre de comunidade, ou seja, uma fuga da comunidade. Gerada em uma sociedade globalizada e desregulada, a nova elite cosmopolita se localiza em uma extraterritorialidade onde a certeza e a segurança entraram em colapso e a idéia de comunidade nunca existiu. Nesse mundo da elite global dos negócios e da indústria cultural só quem tem espaço no palco é quem tem capacidade de participar do jogo do consumo, não havendo espaço para realidades feias e duras.

É bastante interessante a forma utilizada por Bauman para alertar o leitor sobre as diferentes concepções de comunidade, no que se refere a quem a utiliza e como é construída. Assim, a "comunidade" da elite global é inteiramente diferente daquela outra "comunidade" dos fracos e excluídos e, conseqüentemente, a noção de "comunidade" para cada um desses grupos corresponde a experiências inteiramente diferentes e a aspirações contrastantes. Quanto à sua construção, o autor afirma que a "comunidade" deve ser tão fácil de decompor como foi fácil de construir: criação e desmantelamento como resultados das escolhas feitas pelos que as compõem. Na modernidade, os vínculos com a comunidade são voláteis, formando comunidades instantâneas, de consumo imediato. $\mathrm{O}$ autor traz a idéia de comunidades estéticas que se formam em torno de ídolos e se caracterizam por sua natureza superficial e transitória, pois os laços que surgem entre os seus integrantes são descartáveis e pouco duradouros.

A comunidade "estética" se contrapõe à comunidade "ética", de compromissos de longo prazo, de "direitos inalienáveis e obrigações inabaláveis" que reafirmam "o direito de todos a um seguro comunitário contra os erros e desventuras que são os riscos inseparáveis da vida individual". Desta forma, o sentido de justiça 
entre os povos na atualidade deve ser pensado tanto no que se refere à redistribuição quanto ao reconhecimento. Bauman, a partir das contribuições de Castoriadis, irá afirmar que o reconhecimento do direito é um convite para um diálogo onde as vantagens e desvantagens das diferenças em questão possam ser discutidas e acordadas. Este reconhecimento da pluralidade de formas que a humanidade pode assumir e o grau de tolerância sustentado por uma política "multiculturalista" cria defesas contra a homogeneização opressiva e a indiferença soberba.

Em contraposição a este caminho do reconhecimento, muitos espaços sociais, como os bairros de luxo, optam pela separação em lugar da negociação da vida em comum, evidenciando a formação da nova concepção de "comunidade" onde a ausência do outro que teima em ser diferente e capaz de causar surpresas desagradáveis é uma forte característica. $\mathrm{O}$ gueto parece mostrar bem este espaço. Loic Wacquant afirma que o gueto combina o confinamento espacial com o fechamento social, sendo ao mesmo tempo territorial e social, e onde se mistura a proximidade/distância física com a proximidade/ distância moral. Os guetos, para Bauman, são lugares reais de onde não se pode sair; verdadeiras prisões que implicam a negação da liberdade para aqueles excluídos e marginalizados. Assim, a vida no gueto não contribui para a comunidade, uma vez que o compartilhamento do estigma alimenta o desprezo e o ódio. Em síntese, o gueto representaria a impossibilidade de comunidade.

Nas pinceladas finais de seu livro, Bauman irá desenvolver uma análise-síntese colocando como ponto central os limites e possibilidades da coexistência e beneficiamento mútuo de uma vida compartilhada por culturas diferenciadas. Em um mundo de "multiculturalismo", a questão se lança em como conciliar, por um lado, o direito de uma comunidade à proteção contra forças assimiladoras administradas pelo Estado ou pela cultura dominante e, por outro, o respeito ao direito dos indivíduos à proteção contra pressões comunitárias que negam ou suprimem a escolha. $\mathrm{O}$ autor introduz a questão: "Qual dos dois direitos é o mais forte - forte o bastante para anular ou pôr de lado as demandas que invocam 
o outro?" e, como resposta sugere que proteger o indivíduo tanto das pressões não-comunitárias quanto das pressões comunitárias é essencial à realização de qualquer das duas tarefas. A universalidade da cidadania, segundo Bauman, é a condição preliminar de qualquer política de reconhecimento significativa.

Enquanto a segurança é uma condição básica para que um diálogo entre as culturas seja frutífero, a comunidade representa o lugar paradisíaco desta tão esperada segurança. A partir desta relação entre comunidade e segurança, o livro Comunidade: a busca por segurança no mundo atual fornece uma rica análise sobre os motivos de a comunidade ser "procurada como abrigo contra as sucessivas correntezas de turbulência global" em um mundo cada vez mais individualizado.

\section{Referências bibliográficas}

ELIAS, Norbert; SCOTSON, John. Os estabelecidos e os outsiders: sociologia das relações de poder a partir de uma pequena comunidade. Rio de Janeiro: Jorge Zahar, 2000.

FROMM, Erich. A arte de amar. São Paulo: Martins Fontes, 2000. 